\title{
Görsel Programlama Dersinde Proje Tabanlı Öğrenme Deneyimine ilişkin Öğrenci Görüşlerinin İncelenmesi
}

Makale geçmişi

\section{Hacer Özyurt ${ }^{1}$ (B) ve Özcan Özyurt ${ }^{2}$ (B) $\quad \begin{aligned} & \text { Makale gelis tarihi: } 9 \text { Ocak } 2017 \\ & \text { Yay ma kabul tarihi: } 12 \text { Nisan } 2017\end{aligned}$ \\ Çevrimiçi yay in tarihi: 5 Haziran 2017}

\begin{abstract}
Öz: Bu çalışmanın amacı Görsel Programlama Dersinde uygulanan proje tabanlı öğrenme yaklaşımına ilişkin öğrenci görüşlerinin incelenmesidir. Çalışma 2015-2016 güz yarıyılında Türkiye'deki bir üniversitenin Teknoloji Fakültesi, Yazılım Mühendisliği Bölümünde yürütülmüştür. Çalışma grubu olarak Görsel Programlama Dersini alan 11 öğrenci seçilmiştir. Ders kapsamında 5 öğrenci bağımsız, 6 öğrenci ise ikişer kişilik gruplar halinde çalışmıştır. Öğrenciler görsel programlama ortamında, belirledikleri konulara yönelik projeler üretmişlerdir. Çalışma sürecinde bireysel çalışan 1 öğrenci ve 2 grup çalışmadan ayrılmıştır. Araştırmada nitel araştırma yöntemi kullanılmış, projelerini başarıyla tamamlayan 4 bireysel ve bir grup olarak çalışan toplam 6 öğrenci ile mülakat yapılmıştır. Elde edilen veriler içerik analizine tabi tutulmuştur. Çalışmadan elde edilen sonuçlar proje tabanlı öğrenme yaklaşımının öğrencilere öğrenme sürecinde önemli katkılar sağladığını ortaya koymaktadır. Bununla birlikte sinırlı da olsa olumsuz yönde görüş ortaya konulmuştur.
\end{abstract}

Anahtar Kelimeler: Proje tabanlı öğrenme, görsel programlama, mühendis lik eğitimi, aktif/işbirlikçi öğrenme

DOI: $10.16949 /$ turkbilmat.285047

\begin{abstract}
This study aims to investigation of students' opinions about project based learning approach implemented in Visual Programing Course. The study was conducted in Technology Faculty, Software Engineering Department of a university in Turkey in 2015-2016 fall semester. 11 students taking Visual Programing Course were chosen as sample group. In the scope of the course 5 students studied independently, 6 students studied in groups consisting of two students. Students produced projects for the subjects they choic e in visual programing environment. During the study an individual participant working alone and 2 groups left the study. Qualitative research method was used in the study, and interviews were conducted with 6 students in total - four individual students and two students studying in a group. The data obtained from interviews were subjected to content analysis. The results of the study show that project based learning approach contributes the learning process of the students at a significant level. However, even if they are in limited numbers there are also negative views about the approach.
\end{abstract}

Keywor ds: Project based learning, visual programing, engineering education, active/cooperative learning

See Extended Abstract

\section{Giriş}

Son y1llarda öğrencilerin öğrenmelerini zenginleştirmek için farklı yöntem ve tekniklerin işe koşulduğu öğrenci merkezli öğrenme ortamları sıklıkla oluşturulmakta ve kullanılmaktadır. Öğrenci merkezli öğrenme ortamlarının oluşturulmasında fazlaca kullanılan yaklaşımlardan biri de proje tabanlı öğrenmedir. Birçok farklı yaklaşımı bünyesinde bulundurma özelliği ile Proje Tabanlı Öğrenme (PTÖ), öğrenciyi merkeze alarak onların öğrenme sürecinde aktif rol oynamaları, kendi öğrenmelerinden sorumluluk duymaları, problem çözmeleri, gerçek yaşamla bağlantı kurmaları ve yaparak-yaşayarak

\footnotetext{
1 Yrd. Doç. Dr., Karadeniz Teknik Üniversitesi, Of Teknoloji Fakültesi, Yazılım Mühendisliği, Trabzon, Türkiye, hacerozyurt@ktu.edu.tr

${ }_{2}$ Yrd. Doç. Dr., Karadeniz Teknik Üniversitesi, Of Teknoloji Fakültesi, Yazılım Mühendisliği, Trabzon, Türkiye, oozyurt@ktu.edu.tr
} 
öğrenmeleri gibi birçok özelliği ile öne çıkmaktadır (Ay, 2013; Bayraktar, 2015; Jeon, Jarrett \& Ghim, 2014). Bunlara ek olarak ürün odaklı, sürece dayalı ve işbirlikçi çalışmalara olanak sağlaması açısından da tercih edilen PTÖ, bireylere bir ürün ortaya çıkarma ve bu ürünü sunma gibi farklı beceriler de kazandırmaktadır (Atıcı ve Polat, 2010).

PTÖ öğrencilere eski bilgilerini organize etme, kullanma ve yaşamda karşılaşacakları problemleri bir senaryo çerçevesinde çözme becerisi kazanmada etkili bir yöntemdir. $\mathrm{Bu}$ yöntemde öğrenci kendi öğrenme sürecini kontrol etmek durumunda kalacaktır. Çoğu zaman sınıf ortamının dışına çıkan bu süreçte gerçek yaşam deneyimleri de öğrenme sürecine dâhil olmaya başlayacaktır (Ay, 2013; Gömleksiz ve Fidan, 2013; Tosun, 2014). Bunların yanında PTÖ, günümüz bireylerinin taşıması gereken özellikler arasında sıralanan kritik düşünme, problem çözme, girişimcilik, yaratıcılık ve bir ekibin parçası olarak yer alma gibi becerilerin kazandırılmasında da önemli bir role sahiptir (Bacanak, Aydın ve Çepni, 2013; Fallik, Eylon \& Rosenfeld, 2008; Yalçın, Turgut ve Büyükkasap, 2009). Nitekim PTÖ yaklaşımında öğrenciler günlük yaşamdan seçilen problemleri çözmek için planlı ve uzun süreli bir çalışma içine girmektedir. Öğrenciler bu süreçte bir ürün ortaya koymak için uğraşmakta, bu ürünün geliştirilmesinden sunumuna kadar geçen süreçte birçok sorunla karşılaşmakta ve bunların çözümlerine yönelik stratejiler geliştirmektedir. $\mathrm{Bu}$ sürece bir bütün olarak değerlendirildiğinde öğrencilerin bu süreç sonunda önemli kazanımlar elde edecekleri söylenebilir (Stewart, 2007).

PTÖ yaklaşımının getirmiş olduğu yenilikçi bakış açılarından birisi de öğrencilerin ilgi ve yeteneklerini ortaya çıkarmasıdır (Atıcı ve Polat, 2010). Nitekim PTÖ ortamlarında öğrenciler kendi ilgi ve yetenekleri doğrultusunda araştırma ve uygulama yapma imkânı bulmaktadır. Bu yaklaşımın sunmuş olduğu avantaj sayesinde öğrenciler kendi konularını seçebilmekte ve kendi yeteneklerini ön plana çıkarabilmektedir. Bu sayede öğrencilerin bireysel özelliklerinin de öğrenme ortamlarına yansıması ve bu doğrultuda daha başarılı olmalar1 ile sonuçlanabilmektedir (Ay, 2013; Bayraktar, 2015; Chen, 2004; Yasin \& Rahman, 2011). Literatürde PTÖ yaklaşımının uygulandığı çalışmalara bakıldığında, bu çalışmaların ağırlıklı olarak ilk-orta ögretim seviyesinde farklı sınıf ve derslerde yapıldığı görülmektedir (Atıcı ve Polat, 2010; Ay, 2013; Baran ve Maskan, 2009; Özdener ve Özçoban, 2004). Bununla birlikte ilk-orta öğretimde olduğu kadar yaygın olmasa da yükseköğretim seviyesinde de son yıllarda yapılan çalışmalar göze batmaktadır (Atıcı ve Polat, 2010; Aydın ve Yel, 2013; Bayraktar, 2015; Özer ve Özkan, 2013). Bu çalışmalar da ağırlıklı olarak eğitim fakültelerinin farklı bölümlerinde okuyan öğretmen adayları ile yürütülmüştür. Ülkemizde mühendislik eğitimi ile ilgili sınırlı sayıda çalışma yapılmış olması PTÖ yaklaşımında da kendini göstermiştir. Nitekim yurtdışındaki literatürde PTÖ ortamlarının mühendislik eğitimi bağlamında değerlendirilmesine yönelik çalışmaların çokluğuna karşın (Abdulaal, Al-Bahi, Soliman \& Iskanderani 2011; Beddoes, Jesiek \& Borrego, 2010; Jeon ve ark., 2014; Palmquist, 2005; Stewart, 2007) ülkemizde bu alanda yapılmış çalışmaların eksikliği dikkat çekmektedir. Mühendislik eğitiminin öncelikli olarak öğrencilerin problem çözme yeteneklerine odaklandığı (Chua, Yang \& Leo, 2014) göz önüne alındığında PTÖ yaklaşımının bu anlayışa oldukça uygun olduğu görülmektedir. Problem çözme becerisinin mühendis adaylarının meslek hayatlarında 
üstlenecekleri görevleri yerine getirirken karş1laşabilecekleri sorunlarla başa çıkmada en önemli yardımcısı olacağı aşikârdır. Mills ve Treagust (2003) bir mühendis tarafından mesleki uygulamalarda gerçekleştirilen hemen her görevin bir proje ile ilişkili olacağını ifade etmektedir. PTÖ yaklaşımının mühendislik eğitimine dâhil edilmesi, mühendis adaylarının iş yaşamlarında karşılaşacakları problem durumları ile baş etmelerinde onlara önemli kazanımlar sağlayabilir. Bu sayede öğrenciler gerçek hayatta karşılaşacakları projelerin benzerleriyle önceden karşılaşma ve bu konuda deneyim kazanma firsatı da yakalamış olacaktır. PTÖ yaklaşımının mühendislik eğitimine entegre edilmesiyle öğrencilere kendi kendine öğrenebilme, problem çözme, yaratıcılık (Chua ve ark., 2014; Frank, Lavy \& Elata, 2003; Zhou, 2012) gibi mesleki gereklilikleri kazanma ya da var olan özellikleri güçlendirmenin yanı sıra bireysel özelliklerini geliştirme şansı da sunulabilecektir. Bununla birlikte bu yöntemin proje süreç yönetimi, zaman yönetimi, kendine güven ve iletişim becerileri gibi mesleki açıdan önemli özelliklerin gelişmesi için de yararlı olduğu söylenebilir (Dori \& Tal, 2000; Jollands, Jolly \& Molyneaux, 2012; Palmer \& Hall, 2011; Zhou, 2012).

Dünya standartlarında eğitim yapabilmek, teknolojinin ve çağın sorunlarına çözüm üretebilen mühendisler yetiştirmek ülkemizdeki mühendislik ve teknoloji fakültelerinin önemli bir sorumluluğudur. Bu sorumluluğu yerine getirme öz denetiminin yapılabilmesi adına mühendislik eğitiminde mühendisliğin doğasına uygun öğretim yaklaşımlarının kullanılması ve değerlendirilmesi önem taşımaktadır. Mason, Shuman ve Cook (2013), çalışmalarında mühendislik eğitiminin hedefleri arasında karşıl aştığı problemleri çözmek için akıl yürüten ve kendi öğrenmelerinin sorumluluğunu alan bireyler yetiştirmeyi saymaktadır. Mühendislik eğitimi bağlamında PTÖ yaklaşımı mühendis adaylarının mesleki gelişimlerinde önemli bir yere sahip olabilir. Ayrıca toplumun sorunlarına çağın getirileri açısından çözüm üretebilen mühendisler yetiştirmek için de önemli bir araç olabilir. Mühendislik bölümlerinde uygulama ağırlıklı eğitim verilmesi ve sorunlara etkili çözüm üretebilen mühendis adaylarının yetiştirilmesi amacı proje tabanlı uygulamaların yaygınlaştırılmasını gerekli kılmaktadır. Bu açıdan bakıldığında genelde mühendislik eğitimi için özelde ise yazılım mühendisliği bölümünde birçok derste PTÖ yaklaşımının getirmiş olduğu avantajlardan yararlanılabilir. Bu durum PTÖ yaklaşımının uygulanması ve değerlendirilmesini gerekli ve önemli kılmaktadır. Bu bağlamda çalışmada yazılım mühendisliği bölümü görsel programlama dersinde PTÖ uygulaması yapılmıştır. Çalışmanın amacı görsel programlama dersinin PTÖ yaklaşımına uygun olarak yürütülmesine ilişkin öğrenci görüşlerinin belirlenmesidir. $\mathrm{Bu}$ amaç doğrultusunda çalışmanın araştırma sorusu, "Görsel Programlama dersinde PTÖ yaklaşımının kullanılmasına ilişkin öğrenci görüşleri nelerdir?” şeklinde oluşturulmuştur.

\section{Yöntem}

$\mathrm{Bu}$ çalışma yazılım mühendisliği öğrencilerinin Görsel Programlama Dersinin proje tabanlı olarak yürütülmesine ilişkin görüşlerinin derinlemesine incelenmesini amaçlayan ve bu doğrultuda nitel araştırma yaklaşımı temel alınarak oluşturulan betimsel bir 
çalışmadır. Bu bağlamda çalışmada öğrencilerin görüşlerini belirlemek için mülakat tekniği kullanılmıştır. Mülakat bireylerin bir konu hakkındaki fikirleri ve ne düşündükleri öğrenmede tercih edilen yollardan birisidir (Yıldırım ve Şimşek, 2008).

\section{1. Çalış̧ma grubu}

Çalışmanın katılımcılarını Türkiye'deki bir üniversitenin Teknoloji Fakültesi, Yazılım Mühendisliği Bölümü, Görsel Programlama Dersini alan toplam 11 öğrenci oluşturmaktadır. Çalışma sürecinde çalışmadan ayrılanlar olmuş ve çalışma 4 bireysel ve 1 iki kişilik grup olarak toplam 6 öğrenci ile tamamlanmıştır. Öğrencilerden 1'i kız 5'i erkektir. Çalışma 2015-2016 güz yarıyılında yürütülmüş̧ür. Araştırma sorusunun yanıtlanması için örneklemin proje tabanlı yöntemi en az bir kere kullanmış olması gerektiğinden Görsel Programlama Dersini takip etmeyi bırakmayan öğrenciler amaçlı örneklem seçimi ile belirlenmiştir.

\subsection{Uygulama süreci}

Çalışma Görsel Programlama Dersi kapsamında bir dönem boyunca yürütülmüş̧tür. $\mathrm{Bu}$ ders 3. sınıf seçmeli dersi olup derste öğrencilere görsel bir programlama dili aracılığı ile masaüstü programlama ve ürün geliştirme yeterliliğinin kazandırılması amaçlanmaktadır. Ders kapsamında görsel programlama aracı olarak Microsoft Visual Studio ortamında C\# dili seçilmiş ve bu ortamda form uygulamaları yapılması hedeflenmiştir. Öğrenciler bu derse kadar birinci ve ikinci sınıflarda genel programlama, veri yapıları, veri tabanı türü temel dersleri almıştır. Bu derste ürün odaklı çalışma, öğrencilerin iş dünyasına ve meslek hayatlarına hazırlanmasında onlara önemli kazanımlar sağlayabilir. Bu bağlamda dersin yürütülmesinde geleneksel yöntemlerin yerine öğrencilerin öğrenme deneyimlerini zenginleştirebileceği ve onlara proje geliştirme sürecinde katkılar sağlayabileceği düşüncesiyle PTÖ yaklaşımı benimsenmiştir. Diğer bir ifade ile öğrenci merkezli farklı yaklaşımlardan bu dersin içeriğine ve hedeflerine yönelik olarak PTÖ yaklaşımının uygun olacağ 1 ve bu doğrultuda etkin bir biçimde kullanılabileceği düşünülmüştür.

Dersin yürütülmesinde, PTÖ yaklaşımının aşamaları (Korkmaz ve Kaptan, 2000) hayata geçirilecek şekilde bir organizasyon yapılmıştır. Bu doğrultuda, ilk hafta dersi alan 11 ögrenci ile PTÖ yaklaşımı hakkında tartışmalar yürütülmüş ve öğrencilere bu yaklaşımla ilgili genel bilgiler verilmiştir. Dersi alan öğrenciler, bu derste bir program yazma ile ilgili temel becerilere sahip olmakla birlikte ortaya bir ürün koyma noktasında süreç çalışması yapmaları konusunda cesaretlendirilmiştir. Ardından öğrenciler bireysel ya da gruplar halinde proje konusu seçiminde serbest bırakılmıştır. Uygulama başlangıcında 11 kişilik öğrenci grubu kendi tercihleri doğrultusunda 5 bireysel ve 3 ikişer kişilik grup halinde organize olmuş ve konularını seçmiştir. $\mathrm{Bu}$ aşamada öğrenciler geliştirecekleri projelere ilişkin planlar yapmışlar ve geliştirecekleri ürünleri özelliklerini ve kullanacakları programlama bileşenlerini belirlemişlerdir. Proje geliştirme aşaması ise hem ders içi hem de ders dışı çalışma olacak şekilde bir süreç olarak planlanmıştır. Ders, her hafta 2 saat olacak şekilde bilgisayar laboratuvarında yürütülmüştür. Laboratuvar ortamında dersin sorumlusu da bulunmuş ve öğrencilerin çalışmalarında onlara rehberlik yapmıştır. Bu sayede sürecin işleyişi, projelerin gelişimi ve öğrencilerin sürece katılımı 
gözlemlenmiştir. Öğrenciler ders saatleri dışında da projeleri ile çalışmışlar ve derse geldiklerinde her hafta ders sorumlusu ile paylaşımlarda bulunmuşlardır. Uygulama süreci boyunca derse devam eden ve dönem sonunda projelerini başarı ile tamamlayan öğrencilerin sayısı altıdır. Diğer beş öğrenci ise ders süreci boyunca projelerini başarıyla tamamlayamamış ve süreçten kopmuştur. Dönem sonunda son derste dersin ürünü olarak ortaya çıkan projeler sunulmuş ve projeler üzerinde değerlendirmeler yapılmıştır. Tablo 1 'de projesini başarıyla tamamlayanların proje konuları ile projelerinin amaç ve içerikleri verilmiştir. Öğrenciler Ogr1, Ogr2, .. , Ogr6 olarak kodlanmıştır. Tablo 1'de görüldüğü gibi, ilk dört öğrenci bireysel çalışmışken son iki öğrenci birlikte çalışmıştır.

Tablo 1. Öğrencilerin proje konuları ve amaçları

\begin{tabular}{|c|c|c|}
\hline Öğrenci kodu & Projenin konusu & Projenin amacı ve içeriği \\
\hline Ogr1 & $\begin{array}{l}\text { Kütüphane } \\
\text { otomasyonu }\end{array}$ & $\begin{array}{l}\text { Amaç: Veri tabanı uygulaması geliştirmektir. } \\
\text { İçerik: Proje kapsamında geliştirilecek yazılım öğrencilerin } \\
\text { herhangi kütüphaneye üye olabilecekleri, kitap ödünç } \\
\text { alabilecekleri, bu ödünç sisteminin takibinin yapılabildiği, } \\
\text { istenilen zamanda gerekli sorgulamaların yapılabildiği bir } \\
\text { üründür. }\end{array}$ \\
\hline Ogr2 & Okey oyunu & $\begin{array}{l}\text { Amaç: Okey oyunu geliştirmektir. } \\
\text { İçerik: Proje kapsamında geliştirilecek yazılım gerçek okey } \\
\text { oyununun özelliklerini taşıan, üç oyuncusunun bilgisayar } \\
\text { tarafindan atandığ1 ve oynatıldı̆̆, bir oyuncusunun ise } \\
\text { yazılımı kullanan kişi olacak şekilde tasarlandığ bir } \\
\text { üründür. }\end{array}$ \\
\hline Ogr3 & Tavla oyunu & $\begin{array}{l}\text { Amaç: Tavla oyunu geliştirmektir. } \\
\text { İçerik: Proje kapsamında geliştirilecek yazllım tavla } \\
\text { oyununun özelliklerini taşıyan, bir oyuncunun bilgisayara } \\
\text { karşı tavla oynayabileceğibir üründür. }\end{array}$ \\
\hline Ogr4 & $\begin{array}{l}\text { Akış diyagramı ve } \\
\text { programlama öğretim } \\
\text { ortamı }\end{array}$ & $\begin{array}{l}\text { Amaç: Akış diyagramı ve algoritma ile programlama } \\
\text { öğretim ortamı geliştirmektir. } \\
\text { İçerik: Proje kapsamında geliştirilecek yazılım algoritma } \\
\text { gösterim biçimlerinden olan akış diyagramları yardımı ile } \\
\text { algoritma tasarlamak, bu algoritmayı çalıştırmak, izlemek ve } \\
\text { bu algoritmanın farklı programlama dillerindeki kod } \\
\text { karşıllklarının otomatik olarak üretilmesini sağlayacak bir } \\
\text { üründür. }\end{array}$ \\
\hline Ogr5, Ogr6 & Satranç oyunu & $\begin{array}{l}\text { Amaç: Satranç oyunu geliştirmektir. } \\
\text { İçerik: Gerçek satranç oyununun özelliklerini taşıyan iki } \\
\text { kişinin karşıllklı olarak oynayabileceği, bir taşı } \\
\text { yapabileceği hamleleri gösteren bir üründür. }\end{array}$ \\
\hline
\end{tabular}




\subsection{Veri toplama aracı}

Çalışmada veri toplama aracı olarak yarı yapılandırılmış mülakat formu kullanılmıştır. $\mathrm{Bu}$ form araştırmacıların birisi tarafından geliştirilmiş, diğeri tarafından kontrol edilerek nihai halini almıştır. Mülakat formundaki sorular öğrencilerin derste temel alınan yönteme ilişkin bakış açılarını farklı yönlerden ortaya koyacak şekilde titizlikle seçilmiştir. Mülakat formundaki soruların açık ve anlaşı1ır olmasına özen gösterilmiştir. Mülakat formu öğrencilere verilmiş ve kendilerine yöneltilen soruları bireysel olarak yanıtlamaları sağlanmıştır. Çalışmanın sonunda, çalışmaya katılan ve ürün ortaya çıkaran toplam 6 öğrenci ile mülakat yapılmıştır. Öğrenciler kimlik bilgilerini gizlemişler, dolayısıyla kimin hangi cevabı verdiği bilinmemektedir. Mülakat soruları aşağıdaki gibidir:

Görsel Programlama dersinde uygulanan proje tabanlı öğrenme hakkındaki görüşleriniz nelerdir?

- Derste kazanilan becerilere ilişkin görüşünüz nedir?

- Bireysel gelişiminiz, bireysel özelliklerinizin kullanımı ve bunların farkında olmanıza ilişsin görüşünüz nedir?

- Çalışma alışkanlıklarınız üzerindeki etkisi nedir?

- Mesleki gelişiminiz üzerindeki etkisi nedir?

- Proje tabanlı öğrenmeye ilişkin olumlu ve olumsuz yönler nelerdir?

- Bu süreçte karşılaştı̆̆ınız sorunlar nelerdir?

- Bunların dişında eklemek istediğiniz neler var?

\subsection{Verilerin anali i}

Çalışma kapsamında mülakatlar sonucu elde edilen nitel veriler içerik analizine tabi tutulmuştur. Öğrenciler Ogr1, Ogr2, ..., Ogr6 olarak kodlanmıştır. Öğrencilerden yazılı olarak elde edilen nitel veriler yanlış anlaşılmaların önüne geçmek için katılımcılara teyit ettirilmiştir. Öğrencilerin sorulara verdikleri yanıtlarda söylemek istedikleriyle araştırmacıların metinlerden anladıkları karşılaştırılmış ve yanlış anlaşılmalar gerekli durumlarda metinlerin yanına alınan notlarla engellenmiştir. Bu aşamadan sonra analizin güvenirliğini arttırmak için araştırmacı üçgenlemesi yapılmış veriler iki araştırmacı tarafından ayrı ayrı tekrar tekrar okunarak kodlamalar yapılmıştır. Bu kodlardan yola çıkılarak temalar ve alt temalar oluşturulmuştur. İki araştırmacının ayrı ayrı yapmış oldukları kodlama ve temalar karşılaştırılmıştır. İki analiz arasındaki önemsiz sayılabilecek tutarsızlıklar üzerinde tartışılıp ortak kararlar alınarak nihai temalara ulaşı1mıştır. Bu sürecin sonucunda elde edilen temalar ve alt temalar frekans bilgileriyle birlikte sunulmuştur. Analizin onaylanabilirliği için temalara ilişkin öğrenci görüşleri yorum katılmadan doğrudan alıntılarla sunulmuştur. Aktarılabilirlik için örnekleme ilişkin seçim yöntemi ve nedeni belirtilmiş ve çalışma süreci açık şekilde betimlenmiştir.

\section{Bulgular}

$\mathrm{Bu}$ bölümde, PTÖ uygulaması bitiminde öğrencilerle yapılan mülakatların analizi sonucunda elde edilen bulgulara yer verilmiştir. Analiz sonucu çıkarılan temalar, alt temalar ve bunlara ilişkin frekans bilgileri kolay görünür olması için şemaya 
dönüştürülmüş ve Şekil 1 'de sunulmuştur. Öğrencilerin proje tabanlı öğrenme deneyimlerine ilişkin görüşleri dört ana tema altında toplanmıştır. Bu temalar "Mesleki Deneyim", “Öğrenme Katkı", "Bireysel Özelliklere Katkı" ve "Araştırmaya Ayrılan Zaman" başlıkları altında bir araya getirilmiştir.

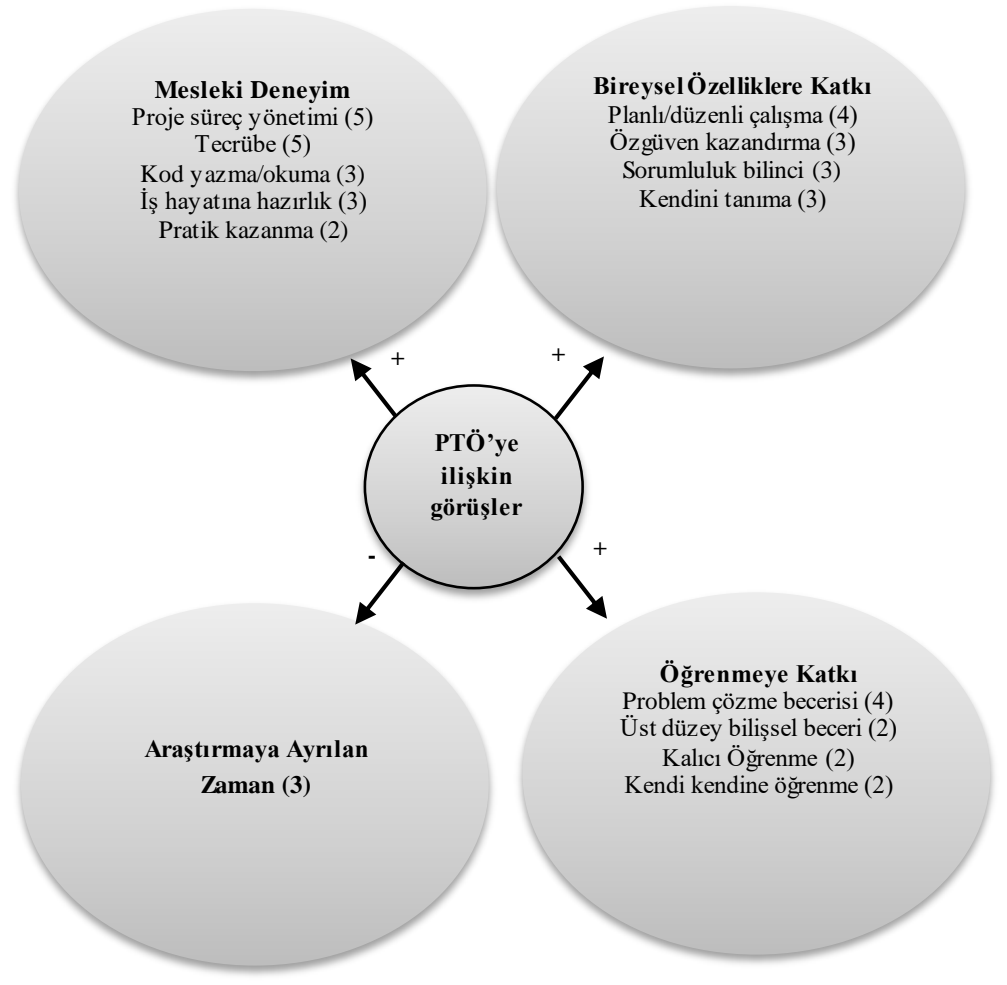

Şekil 1. Veri analizi sonucu elde edilen ana tema ve alt temalara ilişkin bilgiler

Şekil 1'de olumlu görüşleri temsil eden temaları gösteren oklar üzerine + simgesi, olumsuz görüssleri temsil eden temayı gösteren ok üzerine - simgesi yerleştirilmiştir. Ayrıca her bir tema/alt temaya ilişkin tekrar edilme sıklığını gösteren frekans bilgileri de ilgili tema/alt temanın yanında belirtilmiştir. Olumsuz görüşü ifade eden ve "Araştırmaya Ayrılan Zaman" olarak adlandırılan tema diğer temalardan bağımsız ve alt tema içermeyen bir yapı sergilemektedir. Bu yüzden yalnızca tekrar edilme sıklığıyla birlikte tek başına gösterilmiştir. Analiz sonucunda elde edilen tema/alt temaların anlaşılabilirliğini kolaylaştırmak için doğrudan alıntılara yer verilmiştir. 
Öğrencilerin görüşlerinden elde edilen "Proje süreç yönetimi”, "Tecrübe”, "Kod yazma/okuma", "IS hayatına hazırlık", "Pratik kazanma" olarak adlandırılan temaların, yazılım mühendisliği mesleği deneyim/tecrübesiyle ilgili olduğu görülmüştür. Bu nedenle ilgili temaların "Mesleki Deneyim" ana teması altında toplanmasının uygun olduğuna karar verilmiştir.

Öğrenciler proje tabanlı öğretim yöntemi ile birlikte proje geliştirme sürecini tanıma ve anlama deneyimi yaşadığından söz etmiştir. Öğrencilerin büyük çoğunluğu $(n=5)$ proje geliştirme süreci içerisinde karşılaşılması olası sorunlar ve bu sorunların üstesinden gelme deneyimlerinin kendilerine katkısı olduğundan söz etmiştir. "Proje süreç yönetimi" alt temasına ilişkin Ogr4 ve Ogr6'nın görüşleri aşağıdaki gibidir;

Ogr4: ...Proje sürecini yaşamış oldum, bu süreç içerisinde çıkabilecek sorunlar nelerdir, bunları nasıl çözerim bunları gördüm, bu açıdan faydalı oldu...

Ogr6: Yazllim geliş̧tirirken süreçleri kontrol etme becerim gelişti... Meslek i olarak proje tabanlı ögrenme bana bir projenin nastl yürütüleceğini, proje yaparken hangi aşamalardan geçileceğini gösterdi...

Öğrencilerin büyük kısmı ( $\mathrm{n}=5)$ proje tabanlı öğretim yönteminin meslekleriyle ilgili uygulamaya yönelik tecrübe edinmelerini sağladığını ifade etmiştir. Ogr3, Ogr5 ve Ogr6'nın “Tecrübe " alt temasına ilişkin görüşleri aşağıdaki gibidir;

Ogr3: ...Yeni edinilen bilgilerin uygulamaya dökülmesini sağlad, uygulama yaparak tecrübelerimizi daha da arttırdl...

Ogr5: ...Bireysel olarak proje yaparak ilerlediğimi, tecrübe kazandığımı düşünüyorum...

Ogr6: ...Zamanla karşılaştı̆̆ın sorunlara çözüm bulurken yeni bir şeyler öğreniyorsun ve tecrübe kazaniyorsun...

Öğrencilerin yarısı $(n=3)$ proje tabanlı öğretim yönteminin kod yazma/okuma deneyimlerine katkısı olduğunu belirtmiştir. Ogr1 ve Ogr6'nın "Kod yazma/okuma” alt temasına ilişkin görüşleri aşağıdaki gibidir;

Ogr1: ...Kodlama yeteneğimin geliştiğini düşünüyorum...

Ogr6: ...Kod yazma ve okuma yeteneğim gelişti...

Öğrencilerin yarısı $(n=3)$ proje tabanlı öğretim yönteminin kullanılmasıyla bir nevi iş hayatının küçük bir provasını yaptıklarını düşündüklerini belirtmişlerdir. Ogr1 ve Og3'ün "İş hayatına hazırlık" alt temasına ilişkin görüşleri aşağıdaki gibidir;

Ogr1: ...Sektöre hazırladı̆̆ını düşünüyorum...

Ogr3: ...Bir mühendis adayının nasıl kodlama yapması gerektiğini ve nasıl bir tasarım sürecinden geçtiğini öğrenmiş olduk. İş hayatına yönelik çalışmalar yaptığımız için proje tabanl geliş̧tirme ile daha çok verim elde edilebileceğini gördüm...

Öğrencilerin bir kısmı $(\mathrm{n}=2)$ proje tabanlı öğretim yöntemi ile teorik bilgileri pratiğe dönüştürme deneyimi kazandıklarını belirtmişlerdir. Ogr3'ün "Pratik kazanma" alt temasına ilişkin görüşleri aşağıdaki gibidir; 
Ogr3: ...Bildiğimiz teorik bilgileri ve yeni öğrendiklerimizi uygulamaya dökmek pratiklik kazandırmış oldu. Teorik öğrenmekten ziyade bu tarz uygulamaların daha başarılı sonuçlar verdiğini gördüm...

Öğrencilerin görüşlerinden elde edilen "Planlı/düzenli çalışma”, “Özgüven kazandırma", "Sorumluluk bilinci" ve "Kendini tanıma" olarak adlandırılan temaların, öğrencilerin bireysel özelliklerine olumlu katkısı olan durumlar olduğu görülmüştür. $\mathrm{Bu}$ nedenle ilgili temaların "Bireysel Özelliklere Katkl" ana temas1 altında toplanmasının uygun olduğuna karar verilmiştir.

Öğrencilerin büyük bir kısmı $(n=4)$ proje tabanlı öğretim yöntemi ile çalışma alışkanlıklarında bir takım değişmeler olduğundan söz etmektedirler. Öğrenciler planlı ve düzenli bir çalışma alışkanlığı edindiğini belirtmiştir. Ogr1, Ogr3 ve Ogr5'in "Planlı/düzenli çalışma" alt temasına ilişkin görüşleri aşağıdaki gibidir;

Ogr1: ...Düzenli olarak kodlama yapma alışkanlığı kazandırdl...

Ogr3: ...Planlı programlı çalışma alışkanlığım gelişti. Çalışmalarımın planlama sayesinde daha da iyi olabileceğini gördüm...

Ogr 5: ...Kendime bir yol ve zaman çizelgesi oluşturmamı sağllyor, sistematik ve programl gitmeme yardımcı oluyor ve bu proje sayesinde verimli çalışma yollarının farkına vartyorum...

Öğrencilerin yarısı $(n=3)$ proje tabanlı öğretim yöntemi ile başarma duygusunun özgüvenlerinde değişim oluşturduğundan söz etmektedirler. Bir projeyi tamamlayabileceklerini görmek ve ortaya bir ürün çıkarabilmenin özgüvenlerini arttırdığını düşünmektedirler. Ogr1, Ogr2 ve Ogr5'in “Özgüven kazandırma” alt temasına ilişkin görüşleri aşağıdaki gibidir;

Ogr1: ...Bir projeyi yapamayacă̆ım şeklinde önyargılarımı yıkmamı să̆ladı. Bir proje yapabileceğimi gördüm...

Ogr2: ...Bir şeyler yapabildiğimi görmek beni her zaman mutlu etmiştir, burada da aynısı oldu, okulun sonlarına doğru yaklaştıkça artık kendime öğrenci de ğil de yazllım mühendisi olarak bakmama sebep oldu...

Ogr5: ...Elimizde kendi yaptı̆̆ımız bir şeylerin olması öz güven veriyor ve bir adım daha atma isteği uyandirlyor...

Öğrencilerin yarısı $(n=3)$ proje tabanlı öğretim yöntemi ile sorumluluk alma ve sorumluluklarını yerine getirme gibi özellikler kazandıklarını düşünmektedirler. Ogr3 ve Ogr5'in "Sorumluluk bilinci" alt temasına ilişkin görüşleri aşağıdaki gibidir;

Ogr3: ...Sorumluluk bilincimizi geliştirdi...

Ogr5: ...Araştırma ve bize verilen sorumluluklarl yerine getirme zorunluluğu hissettirmesi, bu şekilde yeni şeyler ögrrenmek gayet güzel bir şey bence... 
Öğrencilerin yarısı $(n=3)$ proje tabanlı öğretim yönteminin mühendislik mesleği açısından kendilerini daha iyi tanımalarını sağladığını düşünmektedirler. Ogr3 ve Ogr4'ün "Kendini tanıma" alt temasına ilişkin görüşleri aşağıdaki gibidir;

Ogr3: ...Bizim eksiğimizi görmemizi sağladı. Proje yaparken eksik yanlarımızı gördük ve bu eksiklerin bu tarz uygulamalı projeler ile giderilebileceğini öğrendik ...

Ogr4: ...Ĕğer gerçekten projenin üzerinde çalışıyorsak kendimizin neler yapabildiğini görme imkânı sağllyor...

Öğrencilerin görüşlerinden elde edilen "Problem çözme becerisi”, "Üst düzey bilişsel beceri", "Kalıcı Öğrenme" ve "Kendi kendine ögrrenme" olarak adlandırılan temaların, öğrencilerin öğrenmeleri üzerindeki olumlu etki ile ilgili olduğu görülmüştür. Bu nedenle ilgili temaların "Ögrrenmeye Katkı" ana teması altında toplanmasının uygun olduğuna karar verilmiştir.

Öğrencilerin büyük bir kısmı $(n=4)$ proje geliştirme süreci içerisinde karşılaştıkları çeşitli mesleki sorunlara çözüm bulmaya çalışmalarının problem çözme becerilerini geliştirdiğini ifade etmektedir. Ogr4, Ogr5 ve Ogr6'nın "Problem çözme becerisi" alt temasına ilişkin görüşleri aşağıdaki gibidir;

Ogr4: ...Ben bu derste, sorunlar üzerinde düşünmeyi ve bir nebze de olsa çözüm üretebilmeyi ögrrendim...

Ogr5: ...Yeni şeyler öğrenirken problemlere çözüm arayarak ilerliyoruz birçok konuda, bu da iyi oluyor...

Ogr6: ...Kişisel olarak sorunlara çözüm bulma yeteneğim arttığını düşünüyorum ...

Öğrencilerin bir kısmı ( $\mathrm{n}=2)$ proje geliştirme süreci içerisinde karşılaştıkları problemler ve bu problemleri çözmek için yürüttükleri zihinsel faaliyetlerin kendileri için yararlı olduğu üzerinde durmuştur. Ogr4'ün "Üst düzey bilişsel beceri" alt temasına ilişkin görüşleri aşağıdaki gibidir;

Ogr4: ...Mantı yürütme ve karar verme gibi yönlerimi geliştirdi...

Öğrencilerin bir kısmı ( $\mathrm{n}=2)$ proje tabanlı öğretim yönteminin onlara yüklediği sorumluluk doğrultusunda kendi çabalarıyla öğrenmenin kalıcılığını vurgulamıştır. Ogr6'nın “Kalıcı öğrenme” alt temasına ilişkin görüşü aşağıdaki gibidir;

Ogr6: ...Proje tabanlı öğrenmenin olumlu tarafi her şeyi kendin araștırıp yaptı̆̆ından daha iyi kafana oturuyor. Öğrenme uzun sürse de bir daha unutmuyorsun ...

Öğrencilerin bir kısmı $(\mathrm{n}=2)$ proje tabanlı öğretim yöntemi ile öğrenmenin ders dışında devam ettiğini, kendi kendine araştırarak bilgi birikimlerini arttırdıklarını belirtmişlerdir. Ogr5'in "Kendi kendine ögrrenme" olarak isimlendirilen alt temayla ilgili görüşü aşağıdaki gibidir;

Ogr5: ...Ders dlşı zamanda araştırma ve öğrenmeye dayall proje gelişstirerek kendime yeni şeyler kattyorum... 
Öğrencilerin yarısı $(n=3)$ proje tabanlı öğretim yönteminde araştırma yapmak ve karşılaşılan sorunlara çözüm bulmak için harcadıkları zamanın oldukça fazla olduğu üzerinde durmaktadırlar. $\mathrm{Bu}$ görüş "Araştırmaya Ayrılan Zaman" olarak isimlendirilmiştir. $\mathrm{Bu}$ temanın diğer temalarla ilgili olmadığı ve yalın bir şekilde belirtildiği için de herhangi bir alt temaya sahip olmadığı görüldüğünden yalnız bırakılmıştır. Ogr5 ve Ogr6'nın bu ana temaya ilişskin görüşleri aşağıdaki gibidir;

Ogr5: ...Araştırma ve alt yapı oluşturmada kendi kendimize ilerleyerek fazla zaman kaybetmemiz bu yöntemin olumsuz yönüydü...

Ogr6: ...Proje tabanlı öğrenmenin olumsuz tarafı çok zamanımızı harclyor olmasl. Bilmediğimiz bir noktayı araştırırken çok zaman kaybettik ...

\section{Tartışma, Sonuç ve Öneriler}

$\mathrm{Bu}$ çalışmada yazılım mühendisliği öğrencilerinin görsel programlama dersinde PTÖ yaklaşımının kullanılmasına ilişkin görüşleri incelenmiştir. Çalışmanın sonuçları öğrencilere göre PTÖ yaklaşımının derste kullanılmasının üç ana boyutta toplanabilen olumlu değişimlere neden olduğunu göstermektedir. Değişimin meydan geldiği boyutların mesleki, eğitimsel ve bireysel özellikler olduğu dikkat çekmektedir. Öğrencilerin ağırlıklı olarak aynı görüşte olduğu mesleki boyut ele alındığında yazılım mühendisliği mesleği ile ilgili pek çok faktörü PTÖ’ünün kullanıldığı ders sayesinde yaşama/tecrübe etme fırsatından söz edildiği görülmektedir. Mesleki deneyim olarak adlandırılan bu boyutun barındırdığı "proje süreç yönetimi", "tecrübe", "kod yazma/okuma", "iş hayatına hazırlık", "pratik kazanma" olarak isimlendirilen faktörlere bakıldığında öğrencilerin yazılım mühendisliği iş hayatının küçük bir provasını yaptıklarını fark ettikleri görülmektedir. Bu aynı zamanda PTÖ’nün doğasında var olan eski bilgileri organize etme, kullanma ve yaşamda karşılaşılabilecek problemleri bir senaryo çerçevesinde çözme becerisi kazanma, sınıf ortamının dışına çıkan gerçek yaşam deneyimleri (Ay, 2013; Gömleksiz ve Fidan, 2013; Tosun, 2014) yapılan çalışmada ortaya çıktığının göstergesidir. Bu sonuca dayanarak PTÖ’nün yazılım geliştirme süreci, bu süreçte karş1laş1labilecek problemler, problemlere çözüm üretebilme ve ortaya ürün çıkarma gibi yazılım mühendisliği mesleğinin temelini oluşturan durumlara eğitimsel anlamda oldukça uygun bir yöntem olduğu söylenebilir.

Bireysel özellikler boyutu ele alındığında öğrencilerin "planlı/düzenli çalışma", "özgüven kazandırma", "sorumluluk bilinci", "kendini tanıma" şeklinde ifade edilen faktörlere dikkat çektiği görülmüştür. Bu faktörler irdelendiğinde PTÖ’nün öğrencilere yazılım mühendisinde olması beklenen kişisel özellikleri (Jollands ve ark., 2012; Palmer \& Hall, 2011; Zhou, 2012) kazandırma adına önemli bir rol oynadığı görülmektedir. Yüksek olasılıkla büyük projelerin bir parçası olarak iş hayatında çalışacak yazılım mühendislerinin "planlı/düzenli çalışma" ve "sorumluluk bilinci" gibi kritik özellikleri barındırması gerekliliği kaçınılmaz görünmektedir. PTÖ'nün öğrencilerin çalışma alışkanlıklarını değiştirdiği, kendilerini tanımaları ve bireysel özelliklerini geliştirmede önemli katkılar sağladığını gösteren çalışmalar da (Ay, 2013; Budak, Nalçacı ve 
Köseoğlu, 2006; Tosun, 2015) göz önünde bulundurulduğunda bu yöntemin mühendislik eğitimine dâhil edilmesinin önemli katkıları beraberinde getireceği aşikârdır.

Eğitimsel boyutun altında yer alan ve öğrencilerin aynı görüşü en sık dile getirdiği "problem çözme becerisi" ile ilgili literatürde özellikle mühendislik eğitiminin odak noktası olarak söz edilmektedir (Chua ve ark., 2014; Lin ve ark., 2013; Rugarcia ve ark., 2000). PTÖ yaklaşımıyla birlikte problem çözme becerilerinin geliştiğini ifade eden öğrenciler "kendi kendine ve kalıcı öğrenme" ve "üst düzey zihinsel becerilere" de vurgu yapmaktadırlar. Eğitimsel boyut bütünüyle değerlendirildiğinde hem mühendislik eğitimi açısından hem de genel eğitim amaçları doğrultusunda öğrenciler üzerinde önemli değişiklere neden olduğu görülmektedir. Öğrencileri kendi öğrenme sürecinde sorumluluk almaya iten bu yöntem, aynı zamanda öğrencilerin ilgi ve yeteneklerine uyum sağlayan (Atıcı ve Polat, 2010) yapısı ile rahat bir öğrenme ortamı oluşmasına katkıda bulunmuştur. Öğrenciler kendi öğrenme hızlarına göre ve kendi seçtikleri konulara göre projelerini araştırıp, yapılandırıp, geliştirdiklerinden öğrendiklerinin kalıcılığına katkıda bulunmuştur.

Öğrencilerin bir kısmı PTÖ’nün tüm olumlu özelliklerinin yanı sıra "araştırmaya ayrılan zaman" in fazla olmasını dezavantaj olarak görmüştür. Benzer şekilde Bayraktar (2015) da çalışmasında PTÖ’nün dezavantajları arasında araştırmanın fazla zaman almasını göstermiştir. Bu durum aslında PTÖ’nün doğasında var olan bir durumdur. Proje geliştirme içinde araştırmayı barındıran uzun soluklu bir süreç olduğundan zaman alması kaçınılmaz görünmektedir. Bu durum dezavantaj gibi görünse de aslında dolaylı olarak bir kısım olumlu alt temanın oluşmasına hizmet ettiği görülmektedir. Nitekim araştırma için ayrılan zaman aktif öğrenme sürecinin yaşandığı dolayısıyla da kalıcı öğrenme, kendi kendine öğrenme, problem çözme ve mantıksal düşünme süreçlerinin yaşanması gibi olumlu pek çok durumun ortaya çıkmasına (Atıcı ve Polat, 2010; Gömleksiz ve Fidan, 2013) zemin hazırlamaktadır.

$\mathrm{Bu}$ çalışma bir ders kapsamında sınırlı öğrencinin katılımı ile yürütülmüş ve yalnızca öğrenci görüşlerine yer vermiş sınırlı bir çalışmadır. PTÖ yaklaşımı ile öğrencinin merkeze alındığı, problem çözme ve üst düzey bilişsel becerileri geliştirdiği düşünüldüğünde bu tür yaklaşımlar özellikle uygulamaya dönük ve ortaya bir ürün çıkacağı düşünülen derslerde etkin bir şekilde kullanılabilir. Nitekim özellikle yazılım mühendisliği başta olmak üzere bilgisayar kodlama ve ürün odaklı derslerin çok olduğu bilgisayar bilimleri ile ilgili meslek derslerinde bu tür uygulamalar öğrencilerin mesleki yaşamlarına hazırlanmada onlara önemli kazanımlar sağlayacaktır. Bu açıdan bakıldığında bu bölümlerde PTÖ temelli uygulamaların artırılması yararlı olacaktır. Bu çalışmaya ek olarak gelecek çalışmalarda PTÖ yaklaşımının kodlama ve ürüne yönelik derslere ilişkin akademik başarı, kalıcılık ve yaratıcılık gibi alanlarda etkileri incelenebilir. 


\section{Investigation of Students' Opinions about Project Based Learning Experience in Visual Programing Course}

\section{Extended Abstract}

In recent years student centered learning environments are often created and evaluated in which different methods and technics are included in order to improve the students' learning. One of the most frequently used approaches used in creating student centered learning environments is project based learning. Project Based Learning (PBL) including several different approach in itself becomes prominent by locating the student at the center with such characteristics which enable students to participate actively to the learning process, be responsible for their own learning, solve problem, connect with real life, learn by doing/living (Ay, 2013; Bayraktar, 2015; Jeon, Jarrett \& Ghim, 2014). PBL has an important role in enabling student to gain such skills as critical thinking, problem solving, entrepreneurship, creativity, participating to a team which is required for individuals (Bacanak, Aydın \& Çepni, 2013; Fallik, Eylon \& Rosenfeld, 2008; Yalçın, Turgut \& Büyükkasap, 2009). One of the innovative perspectives brought by PBL approach is to find out the interest and skills of the students (Atic1 \& Polat, 2010). There are lots of studies which use the PBL approach in literature. It is seen that these studies have been carried out in different grade and courses at primary-secondary school level (Atıc1 \& Polat, 2010; Ay, 2013). Besides, there are also studies conducted at higher education level in recent years even if they are not as much as the ones at primary-secondary school level (Atıc1 \& Polat, 2010; Aydın \& Yel, 2013; Bayraktar, 2015; Özer \& Özkan, 2013). These studies are carried out with candidate teachers studying at different departments of educational faculty. The fact that there are studies about engineering education in very limited numbers in our country is also valid for PBL approach. However, there lots of studies conducted with different engineering students based on PBL approach in international literature (Abdul aal, Al-Bahi, Soliman \& Iskanderani 2011; Beddoes, Jesiek \& Borrego, 2010; Jeon et al., 2014; Palmquist, 2005; Stewart, 2007). The fact that practice weighted education is given in engineering department may require to extend the use of project based practices. In this regard, advantages of PBL can be utilized in engineering education generally and in many courses in software engineering specifically. The study aims to investigation of the students' opinions about PBL approach practice in Visual Programing course.

In this study, qualitative research method was used. Participants of the study consist of 11 students taking Visual Programing course in Technology Faculty, Software Engineering Department of a university in Turkey. The study was conducted in fall semester in 20152016 in the scope of visual programing during a semester. Visual Programing course is 3rd grade selective course and in the course it is aimed to enable students to gain skills for making desktop programing and creating products with a visual programing language. Language C\# in Visual Studio environment is chosen as visual programing tool in this course. Students take such fundamental courses as general programing, data structure, and 
database in the first and second grades till third grade. At the first week of the course general information about PBL approach were given to 11 students taking the course. At the beginning of the practice, group consisting of 11 students was organized as 5 individual students and 3 groups consisting of 2 students and chose their subjects. The course was carried out for two hours in computer laboratory every week. At the end of the semester, products of 6 students - 4 individual students and a group consisting of 2 students - who continued the course and produced their project successfully came out. Other student failed to complete their project during the course and broke away from the process. At the end of the semester projects came out as the products of the course were presented in the last course and evaluations were made for the projects. Students were coded as Std1, Sdt2, ..., Std6. The first four students studied individually and Std5 and Std6 studied in group. Interviews were made with the regarding students at the end of the process. Semi-structured interview form which is developed by researchers was used as data collecting tool. In order to enable the validity and reliability of the study, expert views were utilized. Quantitative data obtained from the interviews were subjected to contend analysis.

According to the results obtained from the study, students' views about PBL approach are mostly positive. It can be also said that there are negative views in limited number. Three themes among four themes where the views of software engineering students are collected demonstrate the positive views, whereas one of them shows the negative views. Among the main themes showing the positive views of the students, the theme "Professional experience" consists of five sub-themes and these themes are the indicators for how it contributes to the professional experiences of the students. Given these sub-themes, it can be said that PBL approach enables students to gain skill for project management process, experience, skill for writing/reading code and practical experience and it prepares students to the professional life. Another main theme showing the positive views of the students in terms of reflections from the practice of PBL approach in visual programing course, is that it contributes the individual characteristics of the students. Sub-themes located under this main theme show that positive changes occurred in personalities of the students during PBL practice. Such items as enabling to gain habit of regular/planned study, self-confidence, sense of responsibility and making them to realize their limits are placed under this main theme. Another main theme on which the positives views of the students focus is the main theme of individual learning. Views about the effects of PBL approach on individual learning of the students are collected under this theme. According to the views of the students, PBL contributes to improve problem solving skills and high level cognitive skills such as logical thinking and deciding, and creates opportunity for permanent and selflearning. Beside positive aspects of PBL approach in important and high numbers, views showing the negative feature of the approach, even if in limited numbers, take the attention. The negative view of the students about the PBL approach is that in this approach research process takes a long time which arises from the nature of the approach. Half of the students participated in the study regard the view that long time is spent for researching in this approach as a negativeness beside the positive aspects of this method. 


\section{Kaynaklar/References}

Abdulaal, R. M, Al-Bahi, A. M., Soliman Y., \& Iskanderani F. I. (2011). Design and implementation of a project-based active/cooperative engineering design course for freshmen. European Journal of Engineering Education, 36(4), 391-402.

Atıcı, B. ve Polat, H. (2010). Web tasarımı öğretiminde proje tabanlı öğrenme yaklaşımının öğrencilerin akademik başarısı ve görüşlerine etkisi. Türk Bilgisayar ve Matematik Ĕ̈itimi Dergisi, 1(2), 122-132.

Ay, Ş. (2013). Öğretmen adaylarının proje tabanlı öğrenme ve geleneksel öğretime ilişkin görüşleri. Hacettepe Üniversitesi Eğitim Fakültesi Dergisi, 28(1), 53-67.

Aydın, S. ve Yel, M. (2013). Proje tabanlı öğrenme ortamlarının biyoloji öğretmen adaylarının öz-düzenleme seviyeleri ve öz-yeterlik inançları üzerine etkisi. Turkish Studies, 8(12), 95-107.

Bacanak, A., Aydın, M. ve Çepni, S. (2013). Fen ve teknoloji öğretmenlerinin proje tabanlı öğretim yöntemi (PTÖY) ile ilgili ihtiyaçlarının incelenmesi. Necatibey Ĕ̆itim Fakültesi Elektronik Fen ve Matematik Ĕ̈itimi Dergisi, 7(1), 1-31.

Baran, M. ve Maskan, A. K. (2009). Proje tabanlı öğrenme modelinin fizik öğretmenliği ikinci sınıf öğrencilerinin elektrostatiğe yönelik tutumlarına etkisi. Dicle Üniversitesi Ziya Gökalp Ĕ̈itim Fakültesi Dergisi, 12 (2009), 41-52.

Bayraktar, H. V. (2015). Proje tabanlı öğrenme yaklaşımı. Journal of International Social Research, 8(37), 709-718.

Beddoes, K. D., Jesiek, B. K., \& Borrego, M. (2010). Identifying opportunities for collaborations in international engineering education research on problem- and projectbased learning. Interdisciplinary Journal of Problem-Based Learning, 4(2), 7-34.

Budak, E., Nalçacı, N. ve Köseoğlu, F. (2006, Eylül). Proje-tabanlı ögrenme yaklaşımında ögretmenlerin karşılaştı̆̆ güçlükler ve yaklaşımın öğrenciler üzerindeki etkileri. VII. Ulusal Fen Bilimleri ve Matematik Eğitimi Kongresi'nde sunulan bildiri, Gazi Üniversitesi, Ankara.

Chen, L. (2004). Cooperative Project-based learning and students' learning styles on web page development. Journal of Educational Technology Systems, 32 (4), 363-375.

Chua, K. J., Yang, W. M., \& Leo, H. L. (2014). Enhanced and conventional project-based learning in an engineering design module. International Journal of Technology and Design Education, 24(4), 437-458.

Dori, Y., \& Tal, R. (2000). Formal and informal collaborate projects: Engaging in industry with environment awareness. Science Education, 84(1), 1-19.

Fallik, O., Eylon, B. S., \& Rosenfeld, S. (2008). Motivating teachers to enact free-choice project-based learning in science and technology (PBLSAT): Effects of a professional development model. Journal of Science Teacher Education, 19, 565-591.

Frank, M., Lavy, I., \& Elata, D. (2003). Implementing the project-based learning approach in an academic engineering course. International Journal of Technology and Design Education, 13(3), 273-288. 
Gömleksiz, M. N. ve Fidan, E. K. (2013). Proje tabanlı öğrenme yönteminin web tasarımı dersinde kullanılmasına ilişkin nitel bir çalışma. Mersin Üniversitesi Eğitim Fakültesi Dergisi, 9(1), 120-135.

Jeon, K., Jarrett, O. S., \& Ghim, H. D. (2014). Project-based learning in engineering education: Is it motivational? International Journal of Engineering Education, 30(2), 438-448.

Jollands, M., Jolly, L., \& Molyneaux, T. (2012). Project-based learning as a contributing factor to graduates' work readiness. European Journal of Engineering Education, 37, $143-154$.

Korkmaz, H. ve Kaptan, F. (2000). Fen öğretiminde proje tabanlı öğrenme yaklaşımı. Hacettepe Üniversitesi Ĕ́itim Fakültesi Dergisi, 20, 193-200.

Lin, J. L., Imbertson, P., Srivastav, K., \& Horn, W. (2016). Engineering report: A tool to facilitate learning for real-world problem solving. Frontiers in Education Conference (FIE) (2016, pp. 1-8). Eire, PA, USA: IEEE.

Mason, G. S., Shuman, T. R., \& Cook, K. E. (2013). Comparing the effectiveness of an inverted classroom to a traditional classroom in an upper-division engineering course. IEEE Transactions on Education, 56(4), 430-435.

Mills, J. E., \& Treagust, D. F. (2003). Engineering education-Is problem-based or projectbased learning the answer. Australasian Journal of Engineering Education, 3(2), 2-16.

Özdener, N. ve Özçoban, T. (2004). Bilgisayar eğitiminde çoklu zeka kuramına göre proje tabanlı öğrenme modelinin öğrenci başarısı üzerine etkisi. Kuram ve Uygulamada Ĕ̈itim Bilimleri Dergisi, 4(1), 147-170.

Özer, D. Z. ve Özkan, M. (2013). Proje tabanlı öğrenme yönteminin fen bilgisi öğretmen adaylarının biyoloji konularındaki bilimsel süreç becerileri üzerine etkisi. International Online Journal of Educational Sciences, 5(3), 635-645.

Palmer, S., \& Hall, W. (2011). An evaluation of a project-based learning initiative in engineering education. European Journal of Engineering Education, 36, 357-365.

Palmquist, S. M. (2005, June). Benefiting professional practice using engineering mathematics: a project-based learning approach. Paper presented at 2005 Annual Conference \& Exhibition of The American Society of Engineering Educ ation, Portland, Oregon.

Rugarcia, A., Felder, R. M., Woods, D. R., \& Stice, J. E. (2000). The future of engineering education I. A vision for a new century. Chemical Engineering Education, 34(1), 16-25.

Stewart, R. A. (2007) Investigating the link between self directed learning readiness and project-based learning outcomes: The case of international masters students in an engineering management course. European Journal of Engineering Education, 32 (4), $453-465$.

Tosun, N. (2014). BÖTE bölümü öğrencilerinin proje tabanlı topluma hizmet uygulamaları dersine ilişkin görüşlerinin incelenmesi. Kastamonu Eğitim Dergisi, 22(3), 961-980.

Yalçın, S. A., Turgut, Ü. ve Büyükkasap, E. (2009). Proje tabanlı öğretim yönteminin öğrencilerin elektrik konusu akademik başarılarına, fiziğe karşı tutumlarına ve bilimsel işlem becerilerine etkisinin incelenmesi. International Online Journal of Educational Sciences, 1(1), 81-105. 
Yasin, M. R., \& Rahman, S. (2011). Problem oriented project based learning (POPBL) in promoting education for sustainable development. Procedia Social and Behavioral Sciences, 15, 289-293.

Yıldırım, A. ve Şimşek, H. (2008). Sosyal bilimlerde nitel araştırma yöntemleri (6. baskı). Ankara: Seçkin Yayıncılık.

Zhou, C. (2012). Integrating creativity training into problem and project based learning curriculum in engineering education. European Journal of Engineering Education, 37, 488-499.

\section{Kaynak Gösterme}

Özyurt, H. ve Özyurt, Ö. (2017). Görsel programlama dersinde proje tabanlı öğrenme deneyimine ilişkin öğrenci görüşlerinin incelenmesi. Türk Bilgisayarve Matematik Ĕ̆itimi Dergisi, 8(2), 244-260.

\section{Citation Information}

Özyurt, H. \& Özyurt, Ö. (2017). Investigation of students' opinions about project based learning experience in visual programing course. Turkish Journal of Computer and Mathematics Education, 8(2), 244-260. 